\title{
Modeling Chilling Requirement and Diurnal Temperature Differences on Flowering and Yield Performance in Strawberry Crown Production
}

\author{
Karen K. Tanino ${ }^{1,3}$ and Ruojing Wang ${ }^{2}$ \\ Department of Plant Sciences, University of Saskatchewan, 51 Campus \\ Drive, Saskatoon, SK, S7N 5 A8 Canada
}

Additional index words. accumulative chilling unit, diurnal temperature difference, early yield, flowering time, modeling, strawberry (Fragaria $\times$ ananassa)

Abstract. In North America, over 800 million strawberry crowns are produced by nurseries each year for the strawberry fruit industry. A modeling approach is a quantifiable method to help nurseries predict optimal crown harvest date and potential fruit yield associated with the annual strawberry crown growing environment. Most available models that quantify growth conditions, e.g., chilling effects, use controlled environment chambers and target prediction of time of strawberry flowering, not fruit yield. This study used commercial field fruit yield data over a 6-year period and five geographically distinct locations to construct models to predict the effects of chilling, diurnal temperature difference, and their interaction with daylength on fruit yield and time to flower. Accumulative chilling unit (ACU) was estimated by using nonweighted (simple, M0) and weighted [Mu (Utah Model), M1, M2] accumulation of effective temperature units. The results showed that flowering time correlated with accumulative chilling hours using either a simple (M0) accumulation model or a weighted accumulation model (Mu, M1, M2). The best correlation of flowering time with ACU was a quadratic function $\left(y=82.27-0.049 x+1.74 e^{-5} x^{2}\right.$, where $y=$ flowering time, $\left.x=A C U\right)$ and effective temperatures were from -2 to $15^{\circ} \mathrm{C}$. By contrast, fruit yield was only correlated with ACU using specific weighted accumulation models. The correlation was influenced by weighting factors and effective or inhibitive temperatures involved in the model. Therefore, temperatures have differential effects on fruit yield and on flowering time. When pooled across regions and years, fruit yield could be predicted only by the weighted accumulation Model 2 (M2), a quadratic function $\left(y=-72.15+0.98 x+0.0022 x^{2}\right)$ of the ACU accumulated from 45 d before crown harvest. Fruit yield response to ACU had an optimal level with yield reduction at other values. By contrast, fruit yield linearly increased with increasing difference in diurnal temperature across years and locations. However, the days to first flower were affected interactively by the diurnal temperature difference and daylength when geographically distinct locations are compared. The greater the difference in diurnal temperature at 2 to 3 months before crown harvest, the higher the subsequent fruit yield and the shorter the flowering time. An accumulative diurnal temperature unit of 180 degree-days resulted in $30 \%$ yield enhancement of Saskatchewan-grown crowns over California-sourced crowns. The greater diurnal temperature difference may be the major contributor to the Northern Vigour ${ }^{\circledR}$ response of strawberry crowns produced in northern latitudes such as Saskatchewan.

The production advantages of vegetatively propagated crops such as potato grown in northern latitudes compared with southern sources has long been known in Europe and North America. Over a 7-year period, Canadian-sourced strawberry (Fragaria ×ananassa Duch.) crowns outperformed California-sourced crowns in each year from at least one Canadian-sourced location (Tanino, 2002; Tanino et al., 2006). Because the highest prices of marketable strawberry fruit occur in the first 2 months of fruiting,

\footnotetext{
Received for publication 24 June 2008. Accepted for publication 18 Aug. 2008.

We gratefully acknowledge funding from Agricultural Development Fund (ADF) and Saskatchewan and Alberta growers providing support for this research work.

We gratefully thank the following collaborators who were instrumental in collecting the primary data on which this model is based: Manjula Bandara, Kristine Krieger, Erl Svendsen, and Gerry Ivanochko; and to the strawberry growers who collected fruit yield data on their production sites and allowed us to use their land: Chas Nakama, Bill Ito, Steve Ozawa, James Lokken, Gary Storey, and Bill King.

${ }^{1}$ Associate Professor.

${ }^{2}$ Current address: Canadian Food Inspection Agency, Saskatoon Laboratory, Seeds, Science and Technology Section, 301-421 Downey Road, Saskatoon, SK, S7N 4L8, Canada.

${ }^{3}$ To whom reprint requests should be addressed; e-mail karen.tanino@usask.ca
}

early yield will be of advantage to California producers. This phenomenon has been termed "Northern Vigour" ${ }^{\circledR}$ " and appears to be environmentally regulated. Chandler et al. (1989) reported on a significant propagation location-dependent effect with higher fruit yields from more northern regions.

Strawberry flower induction has been shown to be significantly affected by temperature, preplant chilling as well as photoperiod (see Darnell et al., 2003 for a review). Although Junebearing cultivars are typically facultative short-day plants (Guttridge, 1969; Hartmann, 1947a), temperature has also been shown to be a significant factor. Heide (1977) concluded that at high latitudes, temperature is as important as photoperiod in controlling flowering in strawberry. Sønsteby and Heide (2006) clearly showed an interaction between temperature and photoperiod in strawberry flower bud induction. Durner et al. (1984) suggested classification of strawberry cultivars into photoperiodic types is inadequate as a result of the strong temperature influence on flowering. The lowest temperature treatment of $18 / 14^{\circ} \mathrm{C}$ produced the highest number of inflorescences compared with the other $22 / 18$, $26 / 22$, or $30 / 36{ }^{\circ} \mathrm{C}$ treatments. Hartmann (1947b) also showed that it is not simply a constant low temperature that is important, but a fluctuating day/night temperature shift that induces more flower buds and fruit formation under short photoperiods. Bish et al. (2002) found lower temperature conditioning $\left(25 / 15^{\circ} \mathrm{C}\right)$ induced higher earlier fruit production than the $35 / 25^{\circ} \mathrm{C}$ treatment. Temperature has long been shown to have a strong interaction with photoperiod (Darrow, 1936; Durner et al., 1984, 1986; Hartmann, 1947a, 1947b; Heide, 1977) and to have a distinct cultivar-dependent response. Depending on the cultivar, Darrow (1936) and Heide (1977) found higher flower bud numbers with progressively lower temperature under increasingly longer daylengths. In most cultivars, the lower field temperature enabled earlier harvest to achieve the same yields (Durner et al., 1986). Darnell et al. (2003) reviewed several studies and concluded that flower induction in strawberry is photoperiodically insensitive at low (10 to $\left.15^{\circ} \mathrm{C}\right)$ and high $\left(25^{\circ} \mathrm{C}\right)$ temperature. At low temperature, flowering is induced under any photoperiod, whereas high temperature prevents flower bud formation.

To quantify the Northern Vigour $^{\circledR}$ response and environmental regulation of strawberry crown quality, temperature, diurnal temperature difference, and daylength were selected as major parameters to construct models for predicting yield potential in this study. Previous studies indicate modeling approaches that are based on physiological responses of plants to their environment have more potential to be successful (Bradford, 2002; Forcella et al., 2000). As mentioned, strawberry physiological responses of vegetative growth and flower induction to temperatures were extensively studied (Darnell et al., 2003; Durner and Poling, 1988; Hytonen et al., 2004; Okimura and Igarashi, 1997; 
Risser and Robert, 1993; Taylor, 2002; Tehranifar et al., 1998). Models that describe chilling or temperature effects on flower initiation using weighted accumulation of chilling units in horticultural crops may be more accurate (Dale et al., 2003; Fulton et al., 2001). The Utah Model was one of the most commonly used weighted models initially developed to predict chilling effect on spring bloom dates (Anderson et al., 1986; Richardson et al., 1974). However, the weighted models are not widely applied in strawberry. In addition, most available models are developed to predict chilling requirement for flower induction, not for fruit yield.

Yield capacity of strawberry can be influenced by more complex environmental factors than flowering. Temperature regulation on yield such as chilling effect is indirect, mediated through flowering time, carbohydrate reserve, and vegetative vigor (Darnell et al., 2003). Furthermore, the optimum chilling temperatures were different for vegetative development, fruit production, and quality formation in strawberry (Lieten, 2006). In addition, yield performance may be associated with photoperiod (Hytonen et al., 2004). Therefore, modeling environmental regulation on yield may be more complex and different from on flowering.

The objectives of this study are to develop models that quantify the effects of chilling temperature, duration, diurnal temperature differences, and daylength on strawberry yield. Based on commercial field data across different years and locations, the developed models aim to predict optimum crown harvest date and crown quality under variable environments for strawberry crown production. Model differences were compared between flowering and yield, and model predictability was also compared with commonly used models.

\section{Materials and Methods}

Experimental sites and yield data collection. Experimental strawberry (Fragaria ×ananassa Duch. cv. Camarosa) crowns were produced in northern regions of Saskatchewan and Alberta (Table 1). Camarosa is a Junebearing cultivar chosen for its early, high-yielding capabilities and wide acceptance within the California market. Saskatchewan-grown strawberry crowns were planted in late May or early June and were harvested in late September or early October. Harvested crowns were immediately shipped to Oxnard, CA (lat. $34^{\circ} 12^{\prime} \mathrm{N}$, long. $119^{\circ} 00^{\prime} \mathrm{W}$ ) and Irvine, CA (lat. $33^{\circ} 67^{\prime}$ $\mathrm{N}$, long. $117^{\circ} 82^{\prime}$ W) where they were planted. Flowering and fruiting subsequently occurred in November and December, respectively, with the first fruit harvest in the last week of December. The productivity of the shipped crowns was tested against strawberry crowns produced at Norcal and Lassen Canyon nurseries in Redding, CA (lat. $40^{\circ} 06^{\prime} \mathrm{N}$, long. $122^{\circ} 40^{\prime} \mathrm{W}$ ) as a yield control for fruit production in California. The yield differences between Canadian- and Califor- nia-produced crowns were thus attributable to differences in the environment in which the crowns were raised. The first 2 months, marketable fruit yield (early yield) was considered as yield and the yield data $\left(\mathrm{kg} \cdot \mathrm{ha}^{-1}\right)$ collected from 1996 to 2003 was used for model development.

Impact of crown harvest date on flowering time. Strawberry crowns were purchased from Norcal nurseries in Redding, CA. Crowns were planted at three locations in the province of Saskatchewan: Outlook (lat. $51^{\circ} 28^{\prime} \mathrm{N}$ ), Pike Lake (lat. $51^{\circ} 90^{\prime} \mathrm{N}$ ), and La Ronge (lat. $55^{\circ} 9^{\prime} \mathrm{N}$ ) on 3 June, 16 May, and 29 May, respectively, of 2000. Plants were planted in a completely random design with four replicates of five plants each, total 20 plants per treatment, with an interrow spacing of $30 \mathrm{~cm}$ and row spacing of $1.5 \mathrm{~m}$. The research plots were maintained following the recommended cultural practices for each region with irrigation occurring throughout the season as necessary. For the treatment of variable crown harvest dates, strawberry crowns were dug at weekly intervals from 6 Sept. until 25 Oct. 2000 and field chilling units were accumulated from $15 \mathrm{Aug}$. to the weekly harvest dates. Crowns were trimmed (leaves were removed) and planted into 10$\mathrm{cm}$ pots filled with SunShine Mix No. 4 (SunGro Horticulture Products, Bellevue, WA). Plants were grown in a greenhouse with a 16-h photoperiod (under supplemental sodium halide lights to bring the intensity to $500 \mu \mathrm{mol} \cdot \mathrm{m}^{-2} \cdot \mathrm{s}^{-1}$ ) and $22 / 16 \pm 2{ }^{\circ} \mathrm{C}$ day and night temperatures. Greenhouse plants were fertilized weekly with 500 ppm of $20 \mathrm{~N}-20 \mathrm{P}-$ $20 \mathrm{~K}$ plus micronutrients and time to first flowering was observed weekly.

Temperature data collection. Temperature data, including hourly and daily temperatures, were all downloaded from the web site of Environment Canada: Climate data online (http://www.climate.weatheroffice.ec. gc.ca/climateData/canada_e.html), except at Pike Lake, where temperatures were measured as a result of unavailability of the

online data source. Air temperature was used for modeling.

Model assumptions and development of the accumulated chilling unit. Effective chilling temperature was reported to be from -2 to $8^{\circ} \mathrm{C}$ (Lieten, 2006; Risser and Robert, 1993; Yanagi and Oda, 1993) and inhibitory effects may exist when the temperature is greater than $25^{\circ} \mathrm{C}$ (Darnell et al., 2003).

Subzero temperatures may have the same effects as the low temperatures (Risser and Robert, 1993) and the optimum chilling temperature for yield occurred at $1.1{ }^{\circ} \mathrm{C}$ (Lieten, 2006). Assumptions for weighted modeling approaches, therefore, were based on variable chilling responses of time to first flower and yield at different temperature ranges; that is, it was assumed a maximum response at optimal conditions, negative effects at adverse conditions, and intermediate responses in between. A weighted score for each temperature range was based on the best data fit indicated by $P$ values and $R^{2}$ and the reflection of plant physiological response to chilling temperatures (Darnell et al., 2003; Lieten, 2006; Risser and Robert, 1993). Weighted models were tested based on different assumptions of effective temperature ranges and weighing factors as Model 1 (M1) and Model 2 (M2) compared with the traditional Utah Model (Mu) (Anderson et al., 1986; Richardson et al., 1974) (Table 2) and nonweighted model (M0). The nonweighted model is a simple accumulation of chilling hours with the assumption of equal plant response at each temperature within an effective temperature range. Chilling units were accumulated from 15 Aug. ( $\approx 45 \mathrm{~d}$ before crown harvest) or 1 Sept. ( $\approx 30 \mathrm{~d}$ before crown harvest).

Modeling diurnal temperature difference on yield and flowering time. Weighted accumulation of days was computed as a diurnal temperature difference unit (DTDU) from 1 July or 1 Aug., 3 or 2 months before crown harvest, respectively. The weighting score was rated depending on the difference of maximal and minimal day temperatures

Table 1. Geographic locations of strawberry crown production sites in Saskatchewan and Alberta, Canada.

\begin{tabular}{llr}
\hline Provinces & Location name & Geographic position \\
\hline Saskatchewan & La Ronge & $55^{\circ} 9^{\prime} \mathrm{N}, 105^{\circ} 16^{\prime} \mathrm{W}$ \\
& Meadow Lake & $54^{\circ} 7^{\prime} \mathrm{N}, 108^{\circ} 31^{\prime} \mathrm{W}$ \\
& Saskatoon & $52^{\circ} 10^{\prime} \mathrm{N}, 106^{\circ} 43^{\prime} \mathrm{W}$ \\
Alberta & Outlook & $51^{\circ} 28^{\prime} \mathrm{N}, 107^{\circ} 3^{\prime} \mathrm{W}$ \\
\hline
\end{tabular}

Table 2. Three models tested for time to flowering and early fruit yield. ${ }^{\mathrm{z}}$

\begin{tabular}{|c|c|c|c|c|c|}
\hline \multicolumn{2}{|c|}{ Utah Model (Mu) } & \multicolumn{2}{|c|}{ Model 1 (M1) } & \multicolumn{2}{|c|}{ Model 2 (M2) } \\
\hline$\overline{\mathrm{T}\left({ }^{\circ} \mathrm{C}\right)}$ & Weighting factors & $\overline{\mathrm{T}\left({ }^{\circ} \mathrm{C}\right)}$ & Weighting factors & $\mathrm{T}\left({ }^{\circ} \mathrm{C}\right)$ & Weighting factors \\
\hline$\leq 1.1$ & 0.0 & $-2-2$ & 1.0 & $<-1$ & -1.0 \\
\hline$>1.1-2.2$ & 0.5 & $>2-5$ & 0.8 & $-1-<0$ & 0.8 \\
\hline$>2.2-8.9$ & 1.0 & $>5-8$ & 0.4 & $0-<2$ & 1.0 \\
\hline$>8.9-12.2$ & 0.5 & $>8-15$ & 0.0 & $2-<5$ & 0.8 \\
\hline$>12.2-15.6$ & 0.0 & $>15$ & -1.0 & $5-<8$ & 0.4 \\
\hline$>15.6-18.3$ & -0.5 & & & $8-<15$ & 0.2 \\
\hline$>18.3$ & -1.0 & & & $15-<25$ & 0.0 \\
\hline & & & & $>25$ & -1.0 \\
\hline
\end{tabular}

zTemperature ranges (e.g., greater than 1.1-2.2) were used for each weighting factor category. Model assumptions: effective temperatures $(\mathrm{T})$ and weighting factors for accumulating chilling unit influenced time to flowering and yield during strawberry crown development. 
(Table 3). Models assumed daily maximum and minimum temperature difference affects yield and flowering time. The greater the diurnal temperature difference, the higher the impact on yield and flowering. To detect the effect of daylength on time to the first flower among geographic locations, DTDU adjusted with daylength by total accumulation DTDU was divided by average daylength $\times 10$.

Data analysis. SAS (The SAS ${ }^{\circledR}$ System for Windows, V8.2; SAS Institute, Inc., Cary, $\mathrm{NC)}$ regression procedure was used for analyzing the relation of yield or flowering time and accumulative chilling units or diurnal temperature difference unit.

\section{Results}

Modeling accumulative chilling units and its relation to flowering time. The time to first

Table 3. Weighting factors used to compute diurnal temperature difference units. ${ }^{ }$

\begin{tabular}{lc}
\hline Max T-Min T $\left({ }^{\circ} \mathrm{C}\right)$ & Weighting factors \\
\hline$>16$ & 2.5 \\
$16->14$ & 2.0 \\
$14->12$ & 1.5 \\
$12->10$ & 1.0 \\
$10->8$ & 0.5 \\
$8->6$ & 0.0 \\
$6->4$ & -0.5 \\
$4->2$ & -1.0 \\
\hline
\end{tabular}

${ }^{2}$ The scores were assigned to the difference of daily maximum temperature (Max $\mathrm{T}$ ) and minimal temperature (Min T) and accumulated by days for 2 or 3 months. Temperature ranges (e.g., 16->14) were used for each weighting factor category. flower varied from 46 to $71 \mathrm{~d}$ after planting the late (25 Oct.) to the early (6 Sept.) crown harvest dates, respectively (Fig. 1). Flowering time was significantly $(P<0.01)$ related to accumulative chilling units (ACU) with both the simple accumulation model (Model 0 ) and weighted accumulation models (Models 1 and 2), although these models gave different ACU scales. However, the effective temperature range had a higher influence on model fit than the weighted scores. When the effective temperature range was expanded to a wider range of -2 to $15{ }^{\circ} \mathrm{C}$ (from 0 to $8{ }^{\circ} \mathrm{C}$ ), the regression had the highest $R^{2}(0.84)$ by Model 0. Weighted models, M1 and M2, did not give a better fit under this expanded temperature range of -2 to $15{ }^{\circ} \mathrm{C}$ (data not shown).

Modeling accumulative chilling units and its relation to yield: specific locations. The ACU from Model 1 with an effective temperature range from -2 to $8{ }^{\circ} \mathrm{C}$ correlated with yield when data were analyzed separately by location (Fig. 2). The correlation of the ACU with yield was in a similar trend for La Ronge either from $45 \mathrm{~d}$ (15 Aug.) or from $30 \mathrm{~d}$ (1 Sept.) before crown harvest. The ACU only correlated to yield when it accumulated from 45 d (15 Aug.) in Outlook. Both locations showed yield responses to ACU during crown development had an optimal level. Yield would decrease when ACU was lower or greater than the optimal ACU level.

The effective temperatures adjusted in Model 2 ranged from -1 to $25^{\circ} \mathrm{C}$ compared
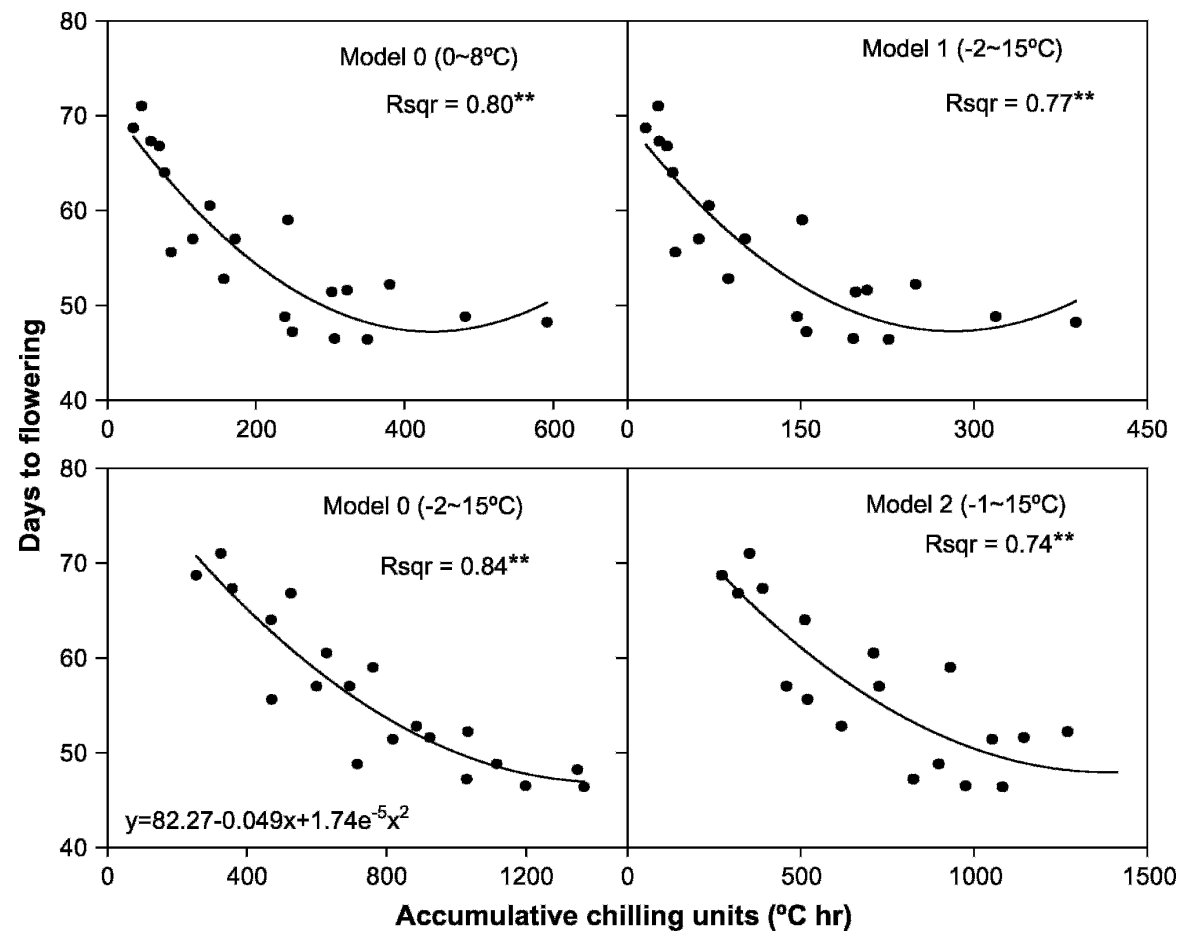

Fig. 1. Modeling days to first flower using chilling units accumulated during strawberry crown development. The strawberry crowns were harvested on various dates from 6 Sept. to 25 Oct. 2000 in weekly intervals and replicated in three growing locations: Outlook $\left(51^{\circ} 28^{\prime} \mathrm{N}\right)$, Pike Lake $\left(51^{\circ} 90^{\prime} \mathrm{N}\right)$ and La Ronge $\left(55^{\circ} 9^{\prime} \mathrm{N}\right)$, Saskatchewan . Model 0 is a nonweighted model representing a simple accumulation of chilling hours (6 Sept. to 25 Oct.) with the assumption of equal plant response at each of two effective temperature ranges. ${ }^{* *} P$ value was significant at 0.01 . with Model 1. Using this model, the ACU when accumulated from 15 Aug. correlated with yield in both locations, La Ronge and Outlook, but not from 1 Sept. (Fig. 3). Meanwhile, the optimal ACU for maximal yield varied with two locations, representing $\approx 150{ }^{\circ} \mathrm{C}$ hour difference between La Ronge and Outlook.

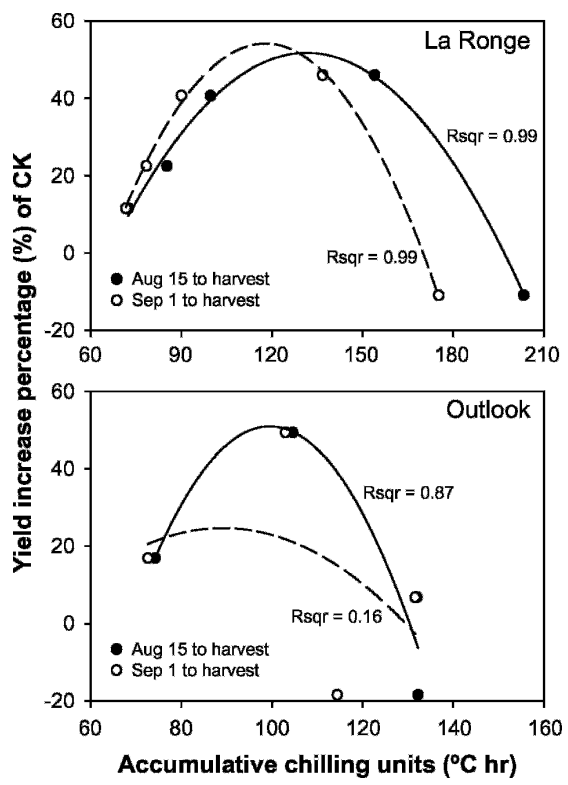

Fig. 2. The correlation of yield increment with accumulative chilling units (ACU) that was estimated by Model 1 using a weighted accumulation from -2 to $8{ }^{\circ} \mathrm{C}$ with an inhibition effect when temperatures were greater than $15{ }^{\circ} \mathrm{C}$ during crown production. ACU was calculated either from $45 \mathrm{~d}$ (15 Aug.), solid line, or from $30 \mathrm{~d}$ (1 Sept.) before crown harvest, dashed line.

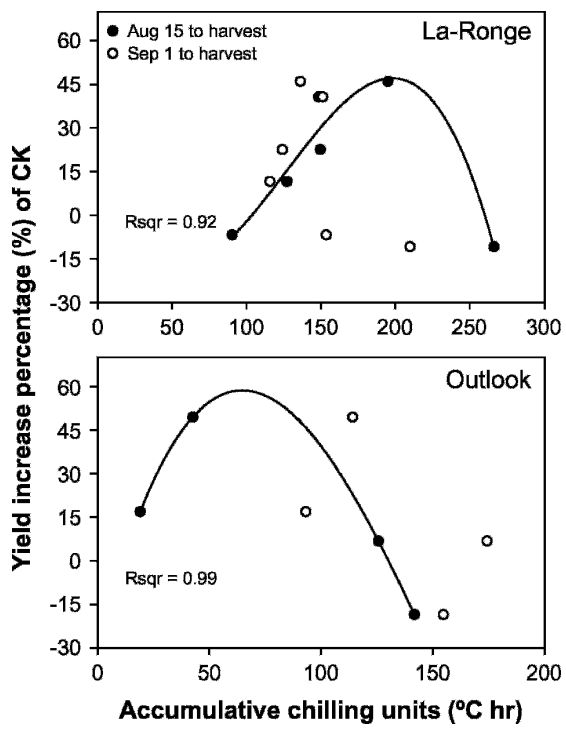

Fig. 3. Modeling yield incremental responses to accumulative chilling units (ACU) for $45 \mathrm{~d}$ ( 15 Aug.) and $30 \mathrm{~d}$ (1 Sept.) before crown harvest using Model 2 for two locations, La Ronge and Outlook, Saskatchewan. Rsqr values are for 15 Aug. data points. 1 Sept. data were nonsignificant.

HortScience Vol. 43(7) December 2008 
Modeling accumulative chilling units and its relation to yield: pooled data. Four models (M0, Mu, M1, and M2) to calculate ACUs were compared with pooled data from five locations over a 6-year period (Fig. 4). The ACUs calculated from $\mathrm{M} 0, \mathrm{Mu}$, and $\mathrm{M} 1$ models were not significantly correlated with the yield increment compared with the control. However, the ACU calculated from M2 was significantly correlated with the yield increase and the yield increase reached its maximum level when the ACU was $\approx 200$ to $250^{\circ} \mathrm{C}$ hour.

Modeling diurnal temperature difference unit and its relation to flowering time. The DTDU was computed by a weighted accumulation of days from 1 July or 1 Aug., 3 or 2 months before crown harvest, respectively. Time to first flower was shorter with the increase of the DTDUs (Fig. 5). When the DTDU was analyzed separately for each location (data not shown) or pooled data from geographically close locations (Fig. 5A), the correlation between flowering time and the unit was significant and had a higher $R^{2}$ value. However, pooled data with relatively distant locations (i.e., La Ronge versus Outlook and Pike Lake), the correlation was not significant and had a lower $R^{2}$ (Fig. 5B). In addition, the time to flower was more closely related to the DTDU accumulated from 1 Aug. (2 months before crown harvest) than from 1 July ( 3 months before crown harvest). The $R^{2}$ values were 0.63 and 0.36 , respectively, from 1 July (versus 0.83 and 0.48 from 1 Aug.) for two close locations and three distant locations.

The correlation indicated by significant levels and $\mathrm{R}^{2}$ values between flowering time and DTDU was increased when the average daylength incorporated into DTDUs both in two geographically close locations (Fig. 5C) and in three distant locations (Fig. 5D).

Modeling diurnal temperature difference unit and its relation to fruit yield. Fruit yield linearly increased with the accumulation of DTDU (Fig. 6). The linear regression $(P>$ $0.01)$ described pooled data across years and locations very well, which clearly indicated little interaction with other environmental factors across years and locations. The DTDU accumulated from 1 July (3 months before crown harvest, $R^{2}=0.68$ ) had a slightly higher $R^{2}$ compared with from 1 Aug. ( 2 months before crown harvest, $\mathrm{R}^{2}=$ $0.64)$, but both were significant at the $P=$ 0.01 level.

Consistent with this result, flower number was positively correlated with chilling accumulation according to models M0 and M2 (Fig. 7). Conversely, runner number per plant was negatively correlated with chilling accumulation (Fig. 7).

\section{Discussion}

Chilling effects for flowering and fruit yield potential. Our results showed days to first flower, or flowering time of strawberry, linearly decreased with the accumulation of chilling units as estimated by all four tested

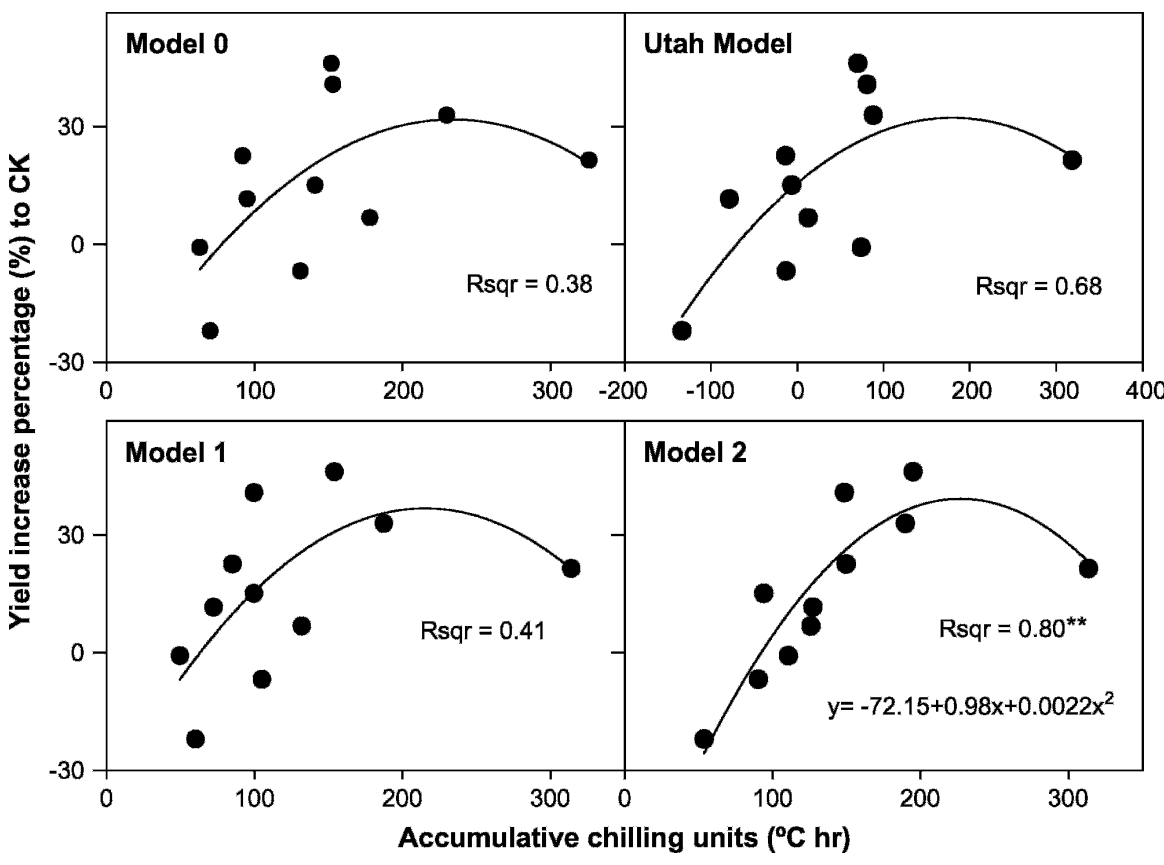

Fig. 4. Model comparisons on yield incremental responses to accumulative chilling units from 15 Aug., $45 \mathrm{~d}$ before crown harvest using Model 0: simple accumulation of chilling units from 0 or greater to $8^{\circ} \mathrm{C}$ or less, Utah Model, Model 1, and Model 2 (Table 2) with pooled data from the 1995 to 2001 (excluding 1997) crown production years and five locations (listed in Table 1, the number of locations may be variable in years). ${ }^{*} P$ value was significant at 0.01 .

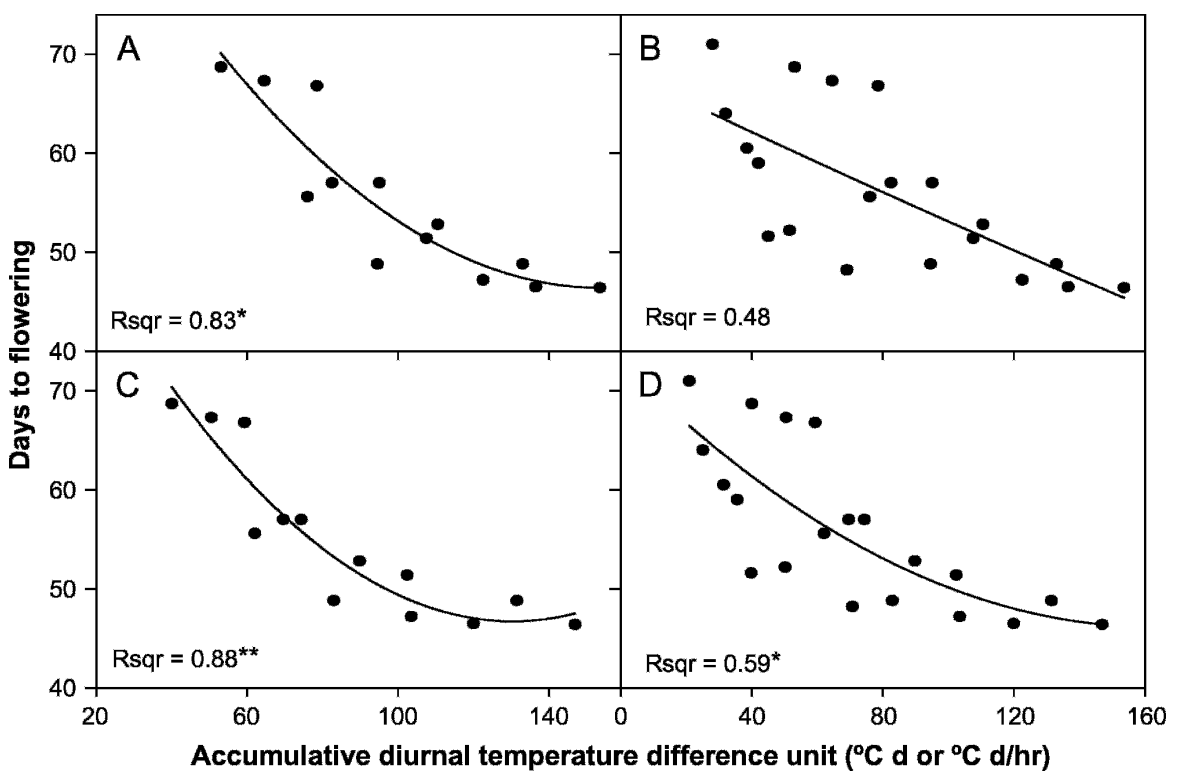

Fig. 5. Modeling days to first flower using accumulative diurnal temperature difference unit (DTDU) accumulated from 1 Aug. (2 months before crown harvest) during strawberry crown production. (A) Pooled data from two geographically close locations (Outlook and Pike Lake) using DTDU; (B) pooled data from three geographically separate locations (Outlook, Pike Lake, and La Ronge) using DTDU; (C) pooled data from the two locations of A using DTDU incorporating daylength (total accumulation of diurnal temperature difference/daylength $\times 10$ ); (D) pooled data from three locations the same as $\mathrm{B}$ using DTDU incorporating daylength the same as $\mathrm{C} .{ }^{*} P$ value was significant at $0.05 ;{ }^{*} P$ value was significant at 0.01 .

models. The correlation of flowering time with chilling units was not largely changed by weighted models that assumed chilling temperatures were not equally effective for flowering. The simple accumulation of chilling units with effective temperatures from -2 to $15^{\circ} \mathrm{C}$ gave the highest correlation of ACUs with the flowering time. This confirmed the chilling temperatures were equally effective on shortening the time to first flower in strawberry as previously reported (Risser and Robert, 1993). However, the effective chilling temperature range for flowering was extended from previous studies. In strawberry, 


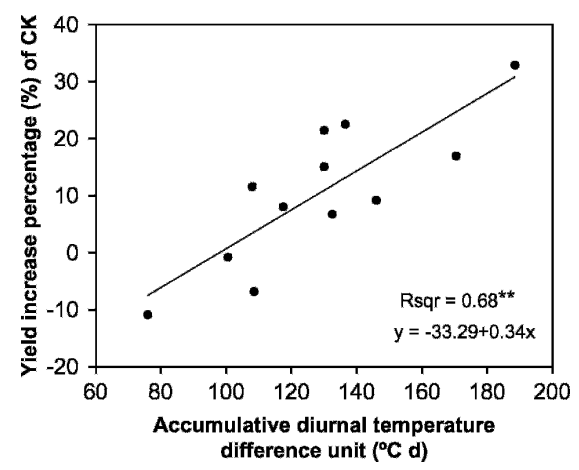

Fig. 6. Modeling yield increase response using accumulative diurnal temperature difference diurnal temperature difference unit that accumulated from 3 months before harvest (from 1 July to harvest) during strawberry crown production. Data were pooled across years and five locations. $* * P$ value was significant at 0.01 .

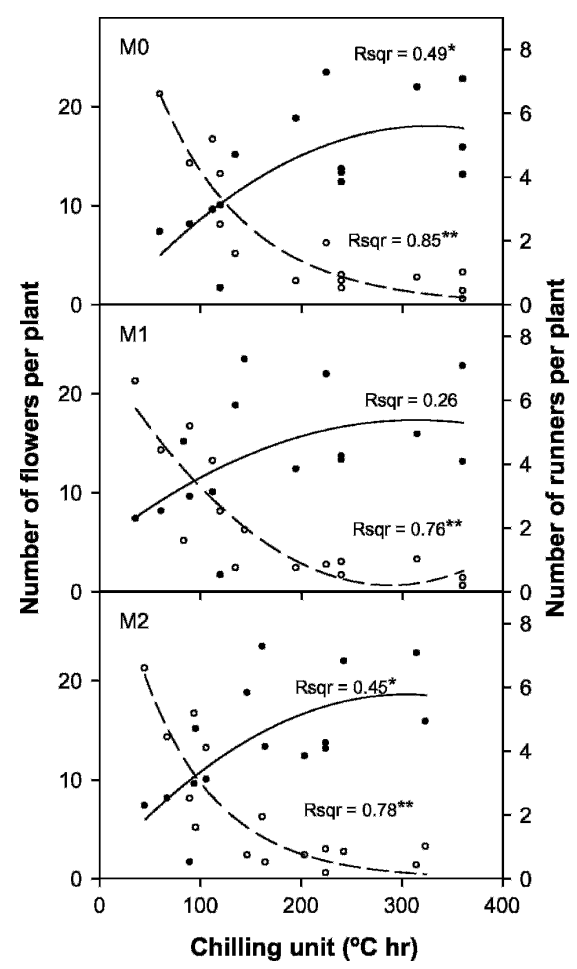

Fig. 7. Relationship of number of flowers (solid line) and number of runners (dashed line) with chilling units calculated according to Model 0 (nonweighted model from 0 or greater to $8{ }^{\circ} \mathrm{C}$ or less), weighted Model 1, and weighted Model 2 in strawberry with chilling treatments.

the chilling temperature for flowering is traditionally defined as hours below 5 (Yanagi and Oda, 1993), 7 (Bigey, 2002), or $8{ }^{\circ} \mathrm{C}$ (Risser and Robert, 1993).

Conversely, pooled fruit yield performance only significantly correlated with the ACUs when estimated by the weighted model, Model 2, across geographic locations and years in this study. Thus, the yield response to chilling temperatures was significantly different from that of time to flower. Chilling temperatures, between -1 and $15^{\circ} \mathrm{C}$, were not equally effective for the yield performance in strawberry. The most effective temperatures were -1 to $5{ }^{\circ} \mathrm{C}$ with negative scores given to temperatures lower than $-1{ }^{\circ} \mathrm{C}$ and higher than $25^{\circ} \mathrm{C}$ in Model 2 . Those latter temperatures would reduce yield potentials. Temperatures between 5 and $15^{\circ} \mathrm{C}$ were less effective for yield potential. Importantly, the ACU accumulation had an optimum level for the yield formation. The over accumulation of the ACUs would lead to yield reduction (Figs. 2 and 3). Fulton et al. (2001) showed no decrease in the number of flowers and shoots per plant when chilling unit was exceeded an optimum level in Paeonia cultivars. Le Mière et al. (1996) indicated that although temperature affected the initial rate of flower production, there was no significant effect on the total number of flowers formed in the primary inflorescence in strawberry but did increase the secondary and tertiary flowers. Our results showed the tendency of increased flower number and significant reduction of runners with excessive ACUs (Fig. 7).

The high fruit yield performance of strawberry should be a result of a balanced relationship of reproductive and vegetative growth. Photoperiod and temperature interactively affect flower and runner development in day-neutral, 'Junebearing', and Everbearing strawberries (Taylor, 2002). Consistently, yield and runner numbers were affected oppositely by the ACUs (Fig. 7). Strawberry plants developed more flowers, whereas the number of runners was reduced with the increase of the ACUs. Conversely, a long chilling period may enhance vegetative growth at the expense of flowering (Avigdori-Avidov et al., 1977; Lieten, 1997; Lieten et al., 1995). Lieten (2006) indicated if strawberry plants were exposed to an excessive amount of chilling, fruit production was decreased and delayed as a result of shorter flower differentiation periods. Nevertheless, a certain quantity of chilling has been shown to enhance flower bud formation of the short-day strawberry plant (Taylor, 2002). Therefore, the chilling requirement for yield potential has fundamental differences and is more complex than the chilling requirement for rate of flowering.

Models and modeling parameters to predict strawberry fruit yield. Comparisons with various chilling unit models in this study allowed a model to be developed that could account for the observed chilling variations. The standard model, the Utah Model, was popularly used as a weighted model, chilling degree hour accumulation, to predict spring flowering phenology (Anderson et al., 1986, Valentini et al., 2004). A simple accumulation of chilling temperature as a nonweighted model, Model 0, was used for predicting chilling requirement in strawberry (i.e., Bigey, 2002). However, neither Utah nor M0 models were correlated with the 'Camarosa' strawberry fruit yield in this study.

In this study, a weighted model with the most effective chill temperature of 0 to $2{ }^{\circ} \mathrm{C}$ to estimate ACU (Model 2) gave the best correlation between the ACUs and fruit yield across production locations and years Although the weight of each temperature range was estimated empirically in Model 2, the best fit of the model should reflect the temperature-dependent rates of physiological responses. Comparing assumptions of Model 1 and Model 2, the effective temperature ranges of chilling requirement for yield potential were between -1 and $5{ }^{\circ} \mathrm{C}$, followed by 5 to $8{ }^{\circ} \mathrm{C}$ and 8 to $15^{\circ} \mathrm{C}$ range. Temperatures between 15 and $25^{\circ} \mathrm{C}$ had no chilling effects, but also no negative effects. Subzero temperatures that were lower than $-1{ }^{\circ} \mathrm{C}$ or temperatures higher than $25^{\circ} \mathrm{C}$ will negatively affect yield performance. According to Model 2, $\approx 200{ }^{\circ} \mathrm{C}$ ACUs were required for optimum yield (Fig. 3). In another study, chilling unit optimums were variable for vegetative development, florescence number, fruit production, and quality in strawberry (Lieten, 2006).

Diurnal temperature difference affecting flowering and yield in strawberry. The greater diurnal temperature difference at cooler temperature regimes is considered to be the major contributor to the Northern Vigour ${ }^{\circledR}$ response of strawberry crowns produced in Saskatchewan. The highest number of achenes was recorded when flowers were subjected to cool temperatures $\left(16 / 11^{\circ} \mathrm{C}\right)$ throughout the ovule differentiation period (Mori, 1998). Our results showed that in contrast to Model 2 in which an optimum ACU occurred, fruit yield linearly increased with increasing diurnal temperature difference units. An accumulative diurnal temperature unit of 180 degree-days resulted in $30 \%$ yield enhancement of Saskatchewan-grown crowns over California-sourced crowns (Fig. 6). This may indicate the cooler night temperature and a greater diurnal temperature difference are the important environmental factors for a higher yield or the Northern Vigour ${ }^{\circledR}$ response. Darnell et al. (2003) speculated the flowering signal may be a sucrosemediated cytokinin-induced response. Day/ night temperature alterations primarily induce changes in net carbon accumulation (see Öquist and Huner, 2003 for a review). Thus, conceivably, the high day/night temperature difference may be accumulating sucrose, which may then induce cytokinin levels with subsequent meristem transition to flowering.

Time to first flower was reduced with quadratically higher accumulations of diurnal temperature difference in geographically closer locations, Outlook and Pike Lake. The linear correlation between diurnal temperature difference unit and time to first flower (Fig. 5B) was improved by integrating daylength among geographically distant locations, Outlook, Pike Lake, and La Ronge (Fig. 5D). This showed flowering time was affected interactively by diurnal temperature difference and daylength. Strawberry flower induction has been shown to be significantly affected by temperature, preplant chilling as well as photoperiod (Darnell et al., 2003; Taylor, 2002 for a review).

A combination of accumulative diurnal temperature units (maximum-minimum temperatures) and application of an expanded 
weighted chilling model from less than $-1{ }^{\circ} \mathrm{C}$ to greater than $25{ }^{\circ} \mathrm{C}$ (Model 2) should have potential to predict yield response and the Northern Vigour ${ }^{\circledR}$ effect in strawberry crown production. This model should be tested on additional cultivars to determine the general nature of this response.

\section{Literature Cited}

Anderson, J.H., E.A. Richardson, and C.D. Kesner. 1986. Validation of chill unit and flower bud phenology model for 'Montmorency' sour cherry. Acta Hort. 184:71-78.

Avigdori-Avidov, H., E.E. Goldschmidt, and N. Kedar. 1977. Involvement of endogenous gibberellins in the chilling requirements of strawberry (Fragaria $\times$ ananassa Duch.). Ann. Bot. (Lond.) 41:927-936.

Bigey, J. 2002. Chilling requirements and compensation for the lack of chilling in strawberry. Acta Hort. 567:269-272.

Bish, E.B., D.J. Cantliffe, and C.K. Chandler. 2002. Temperature conditioning and container size affect early season fruit yield of strawberry plug plants in a winder, annual hill production system. HortScience 37:762-764.

Bradford, K.J. 2002. Application of hydrothermal time to quantifying and modeling seed germination and dormancy. Weed Sci. 50:248260.

Chandler, C.K., E.E. Albregts, and C.M. Howard. 1989. Influence of propagation site on the fruiting of three strawberry clones grown in a Florida winter production system. Proc. Fla. State. Hort. Soc. 102:310-312.

Dale, A., A. Sample, and E. King. 2003. Breaking dormancy in red raspberries for greenhouse production. HortScience 38:515-519.

Darnell, R.L., D.J. Cantliffe, D.S. Kirschbaum, and C.K. Chandler. 2003. The physiology of flowering in strawberry. Hort. Rev. (Amer. Soc. Hort. Sci.) 28:325-349.

Darrow, G.M. 1936. Interrelation of temperature and photoperiodism in the production of fruitbuds and runners in the strawberry. Proc. Amer. Soc. Hort. Sci. 34:360-363.
Durner, E.F., J.A. Barden, D.G. Himelrick, and E.B. Poling. 1984. Photoperiod and temperature effects on flower and runner development in day-neutral, Junebearing, and Everbearing strawberries. J. Amer. Soc. Hort. Sci. 109:396400.

Durner, E.F. and E.B. Poling. 1988. Strawberry developmental responses to photoperiod and temperature: A review. Adv. Strawberry Prod. $7: 6-15$.

Durner, E.F., E.B. Poling, and E.A. Albregts. 1986. Early season yield responses of selected strawberry cultivars to photoperiod and chilling in a Florida winter production system. J. Amer. Soc. Hort. Sci. 111:53-56.

Forcella, F., R.L. Benech-Arnold, R. Sanchez, and C.M. Ghersa. 2000. Modeling seedling emergence. Field Crops Res. 67:123-139.

Fulton, T.A., A.J. Hall, and J.L. Catley. 2001. Chilling requirements of Paeonia cultivars. Scientia Hort. 89:237-248.

Hartmann, H.T. 1947a. The influence of temperature on the photoperiodic responses of several strawberry varieties grown under controlled environment conditions. Proc. Amer. Soc. Hort. Sci. 50:243-245.

Hartmann, H.T. 1947b. Some effects of temperature and photoperiod on flower formation and runner production in the strawberry. Plant Physiol. 22:407-420.

Heide, O.M. 1977. Photoperiod and temperature interactions in growth and flowering of strawberry. Physiol. Plant. 40:21-26.

Hytonen, T., P. Palonen, K. Mouhu, and O. Junttila. 2004. Crown branching and cropping potential in strawberry (Fragaria $\times$ ananassa Duch.) can be enhanced by daylength treatments. J. Hort. Sci. Biotechnol. 79:466-471.

Le Mière, P., P. Hadley, J. Darby, and N.H. Battey. 1996. The effect of temperature and photoperiod on the rate of flower initiation and the onset of dormancy in the strawberry (Fragaria $\times$ ananassa Duch). J. Hort. Sci. 71:361-371.

Lieten, F. 1997. Effects of the chilling and nightbreak treatments on greenhouse production of 'Elsanta'. Acta Hort. 439:633-639.

Lieten, F., J.M. Kinet, and G. Bernier. 1995. Effect of prolonged cold storage on the production capacity of strawberry plants. Scientia Hort. 60:213-219.

Lieten, P. 2006. Chilling unit model for greenhouse production of strawberry cv. 'Elsanta'. Acta Hort. 708:381-388.

Mori, T. 1998. Effect of temperature during flower bud formation on achene number and fresh weight of strawberries. Hort. Sci. 67:396-399.

Okimura, M. and I. Igarashi. 1997. Effect of photoperiod and temperature on flowering in Everbearing strawberry seedlings. Acta Hort. 439:605-608.

Öquist, G. and N.P.A. Huner. 2003. Photosynthesis of overwintering evergreen plants. Annu. Rev. Plant Biol. 54:329-355.

Richardson, E.A., S.D. Seeley, and D.R. Walker. 1974. A model for estimating the completion of rest for 'Redhaven' and 'Elberta' peach trees. HortSci. 9:331-332.

Risser, G. and F. Robert. 1993. What cold treatments promote growth in strawberry. Acta Hort. 348:381-383.

Sønsteby, A. and O.M. Heide. 2006. Dormancy relations and flowering of the strawberry cultivars Korona and Elsanta as influenced by photoperiod and temperature. Scientia Hort. 110(1):57-67.

Tanino, K.K. 2002. Northern vigour of strawberry crowns and garlic: Initiation of commercialization into domestic and foreign markets, research and industry agrologists training. Final Report, Agri-Food Innovation Fund, AFIF \#97000353.

Taylor, D.R. 2002. The physiology of flowering in strawberry. J. Amer. Soc. Hort. Sci. 109:396400.

Tehranifar, A., P. Lemiere, and N.H. Battey. 1998. The effects of lifting date, chilling duration and forcing temperature on vegetative growth and fruit production in the Junebearing strawberry cultivar Elsanta. J. Hort. Sci. Biotechnol. 73:453-460.

Valentini, N., G. Me, F. Spanna, and M. Lovisetto. 2004. Chilling and heat requirement in apricot and peach varieties. Acta Hort. 636:199-203.

Yanagi, T. and Y. Oda. 1993. Effects of photoperiod and chilling on floral formation of intermediate types between June- and Everbearing strawberries. Acta Hort. 348:339-346. 